\title{
O TEATRO PERFORMÁTICO NA CENA CONCEITUAL ${ }^{1}$
}

\author{
Julia Elena Sagaseta ${ }^{2}$
}

Resumo

Este artigo analisa o teatro performático, e o relaciona com o teatro pós dramático identificando algumas diferenças entre ambos. O texto aborda a teatralidade presente no trabalho de vários artistas conceituais (Wiener Aktionismus, Yasumasa Morimura, Gilbert and George, Marina Abramovic, Marcel-lí Antúnez Roca), bem como analisa um grupo de artistas contemporâneos de Buenos Aires, que podem ser considerados como performativos e conceituais, sendo que entre estes alguns estão relacionados com o espaço tecnológico.

Palavras-chave: teatro performativo, cena conceitual, espaço tecnológico.

\section{Abstract}

This article summarizes performative theater, while relating it with postdramatic theater and establishes some differences. It studies the theatricality present in many work by conceitual artists (Wiener Aktionismus, Yasumasa Morimura, Gilbert and George, Marina Abramovic, Marcel-lí Antúnez Roca) and then it delves on the analysis of a group of works from Buenos Aires in the last years, which can be considered as performative and conceitual, some of them including a clear anchor in the technological space.

Keywords: performative theater, conceitual scene, technological space.

\section{Certas precisões}

O teatro performático -aquele que rechaça o textocentrismo, propõe uma relação igualitária entre as distintas linguagens da cena, uma interrelação artística forte, singulariza mais o teatro de apresentação que a representação de uma história, o ator e os recursos atorais do que a personagem- incrementa a teatralidade porque não oculta os procedimentos. Pelo contrário faz chocar o real contra o realismo como estética e desta maneira expande os limites do teatro, o faz cruzar as fronteiras tradicionalmente estabelecidas e encontrar-se, e se mistura com outras expressões artísticas. Falo de teatro"performático”e não de teatro"pós-dramático"(ainda que coincido com muito do que se descreve com este nome) não porque queira fazer outra taxonomia. De fato rechaço as

${ }^{1}$ Tradução do espanhol por André Carreira.

${ }^{2}$ Professora do Instituto Universitario Nacional del Arte Buenos Aires. 
taxonomias na arte. Se falo de teatro performático é porque não faço uma leitura que tenha a ver com uma tradição e um predomínio da textualidade, mas sim leio o que ocorre no teatro atual como algo muito próximo ao que sucede no campo da performance.

Sabemos que esta forma artística mudou muito desde seus inícios nos anos 70 para a variedade de expressões atuais (o que faz com que atualmente esta quase seja aquilo que cada performer determine), e seu intenso contato com a tecnologia. Deixando de lado a linha que liga performance à antropologia e aos estudos culturais, e que vem de Richard Schechner e da academia norte americana, é inquestionável que na performance atual cresceu a carga de teatralidade. Também neste terreno se produziram os encontros mais fortes.

A performance está muito ligada à arte conceitual, seja como parte da mesma segundo alguns autores, seja como continuadora desta arte segundo outros. Mas, sem dúvidas muitas formas da arte conceitual são performáticas. E essas expressões também estão carregadas de teatralidade. Desde a perspectiva das artes visuais não se reconhece essa teatralidade e desde o teatro ela é ignorada. É hora de que ambas se encontrem.

\section{Teatralidade em artistas conceituais}

É estranho que isso ocorra quando alguns artistas conceituais foram explícitos: Herman Nitsch, um dos integrantes do Acionismo Vienense, criou dentro do mesmo, o Teatro de Orgia e Mistério. E foi dentro dessa forma cênica, ritual e ligada ao body art, onde se faziam as ações do grupo.

Yasumasa Morimura realiza toda sua obra desde um grau de teatralidade muito forte. Ele é o criador e o ator da mesma. Em seu trabalho propõe o encontro Oriente-Ocidente (ação difícil para ele ao implicar em ruptura de raízes), que produz artisticamente com uma temática do Ocidente e uma técnica de reprodução da personagem (nas fotos, particularmente) que o aproxima ao onnagata do teatro Kabuki.

Morimura intervêm em quadros famosos na série História da Arte, quadros estes nos quais seu rosto aparece como a Mona Lisa, como uma das Meninas, como Frida Khalo ou como as Majas de Goya. Ou trabalha com estrelas de Hollywood e cenas de filmes famosos. Nas fotos em que ele é o protagonista travestido como Vivian Leight em $E$ o vento levou ou como Marilyn Monroe em alguma de suas poses famosas.

As estátuas viventes de Gilbert e George são também teatrais: na ambientação, no figurino, na maquiagem e também, no movimento dos corpos. 
A mesma coisa ocorre com algumas performances de Marina Abramovic, como Cleaning the mirror realizada em 1995 em Nova York enquanto se desenvolvia a Guerra dos Balcãs. Abramovic estava sentada no chão, vestida com uma roupa branca comprida e rodeada de ossos com restos de carne e sangue que ela limpava com uma escova. Era uma ação apresentativa, não havia personagens. A dor, a emoção do rosto (compungido, com lágrimas nos olhos), eram produzidas pelos fatos da realidade (os fatos bélicos que estavam destruindo a pátria da artista) mas a ação tomava elementos teatrais: objetos, figurino, espaço, uma história dolorosa que se compartilhava através da metáfora da limpeza.

Em outra performance, Seven Easy Pieces, Abramovich homenageou a uma série de artistas repetindo as ações destes. Neste caso representou personagens. Foi, por exemplo, Joseph Beuys em Como explicar arte a uma lebre morta. Vestiu uma roupa similar à que aquele artista havia posto em sua ação, cobriu o rosto com matéria pictórica e carregou a lebre nos braços.

Marcel-lí Antúnez Roca, um dos fundadores da Fura del Baus que se separou do grupo faz tempo, realiza performances nas quais o visual, o tecnológico e o teatral se fusionam. Trabalha com robótica e com entorno audiovisual interativo. Como Sterlac (o performer australiano das experiências ciborgue) seu corpo passa a ser o de um”homem pós-orgânico"(SIBILIA, 2009) já que se introduzem tecnologias digitais.

\section{Cena performática e conceitual}

O teatro performático (ou pós-dramático) é, creio, o mais interessante da cena atual ou, pelo menos é através desse caminho que o teatro encontra as respostas mais sólidas para suas inquietações de mudança. Acerta Lehmann quando destaca a ruptura com a dramaturgia, com o textocentrismo, porque sair dessa sujeição à literatura foi o que permitiu ao teatro expandir suas fronteiras. Mas não me parece, como assinala o crítico alemão, que exista outro tipo de dramaturgia para este teatro (ele se centra quase absolutamente em Heiner Müller e em particular em Descrição de uma paisagem). Penso que o teatro performático apela para qualquer textualidade, seja uma escritura literária ou não literária ${ }^{3}$, seja cinematográfica ${ }^{4}$ ou das artes visuais. Neste sentido, a cena conceitual é interessante para esta reflexão.

Claro que para falar deste tipo de cena (e do teatro performático ou do pós-dramatico) deve-se sair do imediato e ir aos grandes nomes. Em primeiro lugar, ao mentor de tudo, Artaud. Sua radical oposição a qualquer forma cênica que signifique a preponderância da palavra ${ }^{5}$, seu empenho em que o teatro seja um espetáculo total que convoque diferentes artes e
${ }^{3} 0$ conceito de pós-dramático é operacional já que se pode tomar qualquer gênero literário. A diretora Analía Couceyro criou Casa de encontros a partir de textos da poeta uruguaia Marosa di Giorgio. 0 jovem diretor Pablo Ramírez fez sua primeira montagem com $A$ terra baldia de Eliot e conseguiu um espetáculo absolutamente performático com teatro de apresentação e percepção fragmentada.

${ }^{4} 0$ diretor Paco Giménez realizou sua encenação Fiori di merda tomando dois filmes de Passolini, Mama Roma e Teorema. Outro diretor, Guillermo Cacacce, concebeu Ajena a partir da matéria jornalística de uma inundação no litoral argentino que cruzou cenicamente com um discurso oposto, o filme Escola de sereias com Esther Williams.

${ }^{51}$ Em vez de insistir em textos que se consideram definitivos e sagrados importa antes de mais nada, romper a sujeição do teatro ao texto e recobrar a noção de uma espécie de linguagem única a meio caminho entre 0 


\section{Urdimento}

(cont.) gesto e 0 pensamento." (ARTAUD, 1978, p. 101). "Afirmo que a cena é um lugar físico e concreto que exige ser ocupado e que se Ihe permita falar sua própria linguagem concreta". (ARTAUD, 1978, p. 410)

6"Falando praticamente, queremos ressuscitar uma ideia do espetáculo total, onde 0 teatro recobre do cinema, do music hall, do circo e da vida mesma o que sempre foi seu. Pois esta separação entre 0 teatro analítico e 0 mundo plástico nos parece uma estupidez" (ARTAUD, 1978, p. 97)

${ }^{7}$ Basta recordar o que significou o encontro com os textos de Artaud para Julian Beck e Judith Malina e consequentemente para sua concepção do Living Theatre. A mesma coisa aconteceu nos anos 60 com Peter Brook. No teatro argentino Emilio García Wehbi tem uma declarada admiração por Artaud e há manifestado isso artisticamente em várias de suas performances (Matadero) formas espetaculares ${ }^{6}$, sua ideia de que a representação deve constituir"poesia no espaço”, não somente têm uma grande atualidade senão que não está, em absoluto, esgotadas ${ }^{7}$.

Depois de Artaud está Kantor. Para mim um nome muito significativo, talvez o mais significativo como influência direta nas formas teatrais performáticas mais importantes do meu país. Pensando na importância que Lehman dá a Robert Wilson e que também Roselee Goldberg outorga a esse diretor, tenho que pensar que talvez na Europa Wilson teve mais peso, no entanto sem Kantor não haveria existido o grupo El Periférico de Objetos. As pegadas do diretor polonês foram, na Argentina, mais importantes não apenas que Robert Wilson como também que Eugenio Barba.

Kantor era um artista que participou de distintas esferas da arte de sua época. Pintava, fez happenings e performances, e teatro. Em consonância com sua atividade de artista conceitual, dava prioridade ao processo sobre o produto final, não criava personagens (ou criava muito poucas). Tomava textos de autores de vanguarda, como Wietkiewicz e os desconstruía para fazer sua obra e a de seus atores, que não deixavam de ser eles (como os gêmeos Janicki, por exemplo) para se transformarem em personagens. Por isso jogava com os papéis femininos ou masculinos ou com qualquer vislumbre de realismo (que seus bonecos destruíam).

Também é preciso colocar nesta lista Robert Wilson, Richard Foreman, Jan Fabre, Pina Bausch, a Fura del Baus, a Societas Raffaello Sanzio de Romeo Castellucci.

\section{Obras}

Abordo centralmente agora o teatro do meu país para estabelecer uma relação entre o teatro e a arte conceitual.

\section{Manifesto vs. Manifesto}

Em 2007 Susana Torres Molina, dramaturga e diretora com uma importante produção desde finais dos anos 60, estreou a peça Manifesto vs. Manifesto. O espetáculo propunha algo não usual no teatro dado que tomava a figura de Rudolf Schwarzkogler, o transgressor artista do Acionismo Vienense, debatia um suposto manifesto deste artista e argumentava sobre os limites da arte.

Schwarzkogler foi quem levou mais aprofundou as propostas de um grupo que conjugava formas da body art muito extremas, já que implicavam em feridas, autoflagelações e, no seu caso, mutilação. Estas agressões se cruzavam às vezes com as ações do Teatro de Orgia e Mistério que dirigia outro acionista, Hermann Nitsch. 
O espetáculo de Torres Molina não tratava de reproduzir as situações vitais de Schwarzkogler, ainda que um ator tomava sua figura na cena. Não se contava uma história, se discutia sobre as formas mais ousadas da expressão artística enquanto em uma televisão podiam-se ver sequências das ações de Schwarzkogler. Isto é, o espaço tecnológico tinha uma força, um impacto muito maior que a posição racional dos seres vivos da cena.

Tratava-se um teatro de representação quando um ator era Rudolf e de um teatro de apresentação quando os outros atores se moviam como eles mesmos, falavam como si mesmos, refletiam sobre o tema e sobre as imagens projetadas dos filmes do Acionismo.

Assim, se confrontavam as ideias de Rudolf explicitadas no Manifesto Apócrifo e suas realizações, com as ações cotidianas dos atores e suas conversações sobre fatos comuns. Momentos que roçavam o sinistro de Rudolf com as passagens humorísticas das situações correntes. Mas todos eram atores e se algum punha em primeiro lugar uma personagem e um artista, os outros se escondiam na cotidianeidade frente às situações temerárias às que se expunham os acionsitas e que se via nas projeções.

Torres Molina colocava o teatro no terreno da arte total e fazia este pensar os limites éticos da arte.

\section{Spa conceitual}

No ano de 2006, Ana Alvarado estreou no Centro Cultural Recoleta a experiência Spa conceitual, uma obra artística de ruptura de limites, difícil de definir como ocorre nestes casos. O que era isso? Uma instalação teatral performática ou uma performance, como definiu Alvarado em alguma entrevista? Importa realmente poder atribuir-lhe uma etiqueta?

A artista partiu de um fato da realidade, a moda dos spa, e fez, com seu grupo, uma projeção irônica desde uma base conceitual que resultou uma linguagem e também uma homenagem a esse tipo de arte.

Alvarado desenvolveu esta obra em um amplo espaço do Centro Cultural Recoleta, um âmbito de arte e de teatro de vanguarda. O lugar se apresentava como um estranho spa com aparelhos de diversos tipos, espreguiçadeiras, objetos, todos bastante estranhos. Os atores, vestidos com batas, recebiam os espectadores que chegavam a um espaço no qual podiam mover-se livremente. Estes se misturavam com os atores, tocavam os objetos ou os ocupavam. Em um lado estava uma atriz de costas, com o torso nu. $\mathrm{O}$ corpo da atriz imobilizado, objetualizado, sofria a intervenção dos espectadores que escreviam nele. 
De repente se ouviam vozes e o público detinha seu recorrido e se aproximava a um pequeno palco. Ali alguns atores começavam a monologar. Os espectadores se sentavam nas cadeiras próximas e escutavam o que resultava em conferências ou confissões.

Spa conceitual resultava uma experiência (arte/teatro) conceitual mas também relacional pois o contacto entre as pessoas presentes era fundamental. Como no trajeto final os espectadores/visitantes se situavam em uma atitude mais teatral não constituíam uma platéia de desconhecidos. Haviam compartilhado o vagar pelo espaço, as surpresas ou a escritura no corpo objeto. Nicolás Bourriaud diz que”a arte contemporânea modela mais do que representa, em lugar de inspirar-se na trama social se inserta nela. (...) A arte é um estado de encontro”(BOURRIAUD, 2008, p.17).

Body art

Em 2008 Sol Rodríguez Seoane, estreou e interpretou sua obra Body art com direção de Miguel Israilevich. Neste caso se armam, redes no espaço conceitual: Rodríguez Seoane é atriz e dramaturga, interessa-lhe o teatro e a escritura em todas suas variantes. A primeira ideia desta obra foi o encontro com outra obra: Manifiesto vs. Manifiesto. A artista se sentiu surpreendida pelo tema, o tratamento e a discussão artística que aquela peça sustentava e propunha. O teatro, então, não era somente histórias contadas.

No entanto, Rodríguez Seoane e o diretor Israirevich não recusaram nenhuma instância. Assim, na sua obra se tratava o tema da arte, em particular a arte corporal, se discutia isso, mas em contraste com a obra que lhe serviu de impulso, os intercâmbios estavam rodeados de elementos paródicos. Entretanto, esses recursos não diminuíram o olhar dirigido para a Arte, ainda que se referia mais ao outro ingrediente presente: a história amorosa, com suas voltas e peripécias. Entendimentos e desentendimentos das duas artistas.

Ao contrário de Manifiesto que trabalhava com uma personagem da realidade e escondia sua história para abordar um suposto documento, aqui a ficção se instalava e se cruzava com nomes e fatos do body art. O corpo, como produtor de prazer estético e amatório e também de dor estética - a amatória -, estava sempre presente.

A obra estava escrita e dirigida com inteligência. O texto apresentava um tratamento não linear e tinha uma correspondência com o espaço e a cenografia minimalista. As roupas, anacrônicas e muito fechadas, funcionavam em oposição aos solilóquios das atrizes (nunca se estabeleciam diálogos) e ao tema, muito mais transgressor. 
Body art conseguia que confluíssem a discussão artística, o diálogo amoroso e a situação teatral em um todo harmônico.

\section{Dolor exquisito}

Esta obra de Emilio García Wehbi e Maricel Álvarez coloca, como poucas, o teatro na cena conceitual. Em primeiro lugar porque Emilio García Wehbi é um artista conceitual e talvez o único na Argentina que faz performance desde as condições do teatral. Em segundo lugar porque realizou um trabalho que seguia na sua proposta ao de uma artista desta linha artística, Sophie Calle.

Em 2007 García Wehbi e Maricel Álvarez estréiam Dolor exquisito, um espetáculo conceitual e artaudiano em um sentido profundo. Explico porque lhe atribuo estes adjetivos e começo pelo segundo. Ainda que se conte um relato, ainda que se escutem palavras, Dolor exquisito não é textocêntrico. As imagens do espaço, as que produzem a atriz, a cenografia e o figurino, o filme, as projeções na cabeça de um boneco, são tão fortes e relatam tanto como o texto falado. Como propunha Artaud, a cena é uma confluência de linguagens sem primazia de uma delas (e particularmente sem primazia do literário). Por outro lado, o título já relaciona a proposta cênica com a obra homônima de uma artista singular.

Como todas as obras de Calle, Dolor exquisito partiu de uma experiência pessoal, uma viagem ao Japão com uma bolsa de estudos e um abandono amoroso porque seu amante não quis esperá-la. Posteriormente, a artista fez pública tal experiência através de uma exposição com fotos, entrevistas e textos. Como sempre em Calle tudo isto se transformou depois em um livro no qual as fotos foram acompanhadas com textos que escreveu.

García Wehbi e Maricel Álvarez viram a exposição de Dolor exquisito em Berlim e adquiriram o livro. Entusiasmados com a autora, pensaram fazer uma obra teatral. Mas a imaginaram em um processo conceitual afim com a própria criação de Calle. Isto é, o que fizeram não foi um trabalho teatral tradicional que houvesse implicado realizar um roteiro com os textos de Calle e com a história das fotos. Pelo contrário, repetiram os passos da artista: foram ao Japão em todos os lugares no quais esteve Sophie, García Wehbi filmou Maricel ali, voltaram, construíram sua obra, buscaram uma série de atores aos que filmaram contando os fatos dolorosos das entrevistas que fez Sophie Calle.

O espetáculo se diluía por momentos, e em outros parecia construirse em camadas que se sobrepunham. O espaço era uma caixa branca na qual sobressaiam as cores do belo figurino, dos objetos que os criadores trouxeram da viagem e o que os espectadores viam no filme feito no Japão, que era 
projetado em uma tela. Enquanto se observavam as imagens, Maricel ia dizendo as palavras escritas por Sophie. Maricel era Sophie quando falava, a representava, mas era ela mesma na tela. Confluíam ao mesmo tempo a representação e a apresentação, a personagem e a atriz, duas viagens, cada uma com sua história.

García Wehbi e Alvarez alcançaram, com seu espetáculo, um efeito similar ao da obra de Calle: surpreender, interessar, impactar.

`Juan Manuel de Rozas (1793-1877) foi governador da Província de Buenos Aires, cargo que naquele momento histórico representava uma quota poder semelhante ao do presidente da república na atualidade.

${ }^{10}$ Mantenho a denominação da ópera, mas é um roteiro de um grande cuidado literário. A música foi composta por Marcelo Delgado [NT].

\section{El matadero ${ }^{8}$}

Este é o título de seis performances que realizou Emilio García Wehbi mas também de uma ópera a que vou fazer referência aqui.

El matadero é um texto clássico da literatura argentina do Século XIX que faz no seu título uma metonímia da situação de violência da época. Escrito em 1840 por Esteban Echeverría, é um conto fortemente político contra o governo autoritário de Juan Manuel de Rosas ${ }^{9}$. García Wehbi, autor do roteiro ${ }^{10}$ e da direção, toma o confronto básico da peça, federais (rosistas) e unitários (opositores) assim como fragmentos do conto e de outras escrituras da literatura gauchesca rosista da época e agrega distintos registros de autores e vozes populares do Século XX.

$\mathrm{Na}$ interrelação artística teatral, a ópera é, logicamente, o gênero privilegiado. Mas se o que se faz é uma encenação performática a interrelação se enriquece e a teatralidade se potencia. Os dois protagonistas da obra, o unitário e o federal (que sustenta o ideologema básico da história -e da realidade- argentina, civilização/barbárie, se enfrentam em suas atitudes, seus registros vocais (um contra tenor e um ator que canta com uma voz ríspida) e musicais, suas textualidades. Disputam o touro/vaca - uma bailarina cujo figurino ostenta genitais masculinos- acompanhada por um coro de seis cantores.

Ainda que exista um relato e se exponha ideologias, o que leva a que a obra se converta em uma peça política, há claros elementos performáticos: Matasete, o federal, assa carne em cena, o touro/vaca é atacada por Matasete com facas que o cerca, e logo ela escapa saltando entre as poltronas dos espectadores perseguida pelos cantores (homens do matadouro). Como na arte conceitual se joga com o perigo, se rompem as redes de contenção.

A encenação é muito impactante nos aspectos cenográficos, nas luzes, figurino, vozes, canto. Todas as linguagens da cena, todas as possibilidades da ópera armam uma trama equilibrada e harmônica. 


\section{A cena conceitual e tecnológica}

A cena atual está marcada pelos efeitos tecnológicos. Quase não há obra onde não se utilize um vídeo ou um filme. Em muitas há tratamentos digitais. Como ocorre nas artes visuais também no teatro há algumas encenações onde a tecnologia ganha uma importância muito maior e se experimenta com ela na busca de outras aberturas. Vejamos alguns exemplos.

Visible

Em 2008, em Tecnocena, Ana Alvarado apresentou Visible, um espetáculo experimental pensado a partir da tecnologia. É outra obra conceitual com maior carga teatral que Spa conceitual, que Alvarado realizou com o grupo La Fase integrado por artistas visuais e teatrais. Contexto do qual advém a forte integração de ambas perspectivas e a decidida posição de experimentar.

O que originou o espetáculo foi uma pesquisa sobre a relação com o objeto tecnológico, sua rápida obsolescência, as habilidades e competências que suscita (Windows, os chats, o idioma do celular, etc.) e de que maneira se poderia encontrar teatralidade em tudo isso.

O espaço cênico estava coberto de cabos e de objetos maquínicos e tecnológicos de distintas procedências e épocas. Essa mistura de anos testificava uma obsolescência impossível de parar. No material de divulgação o grupo assinala:

a velocidade a que se renovam e substituem os artefatos eletrônicos (especialmente os associados à computação e à telefonia celular) nos faz a correr mais rápido para permanecer no mesmo lugar (...). No caminho vão ficando os cadáveres, e cada fetiche tecnológico que adquirimos vem com seu certificado de obsolescência iminente (...). Este projeto pretende redimir estes objetos reintroduzindo-os no circuito material (palco) para vincular-se sem hierarquias em relação às"novas tecnologias"que os condenaram ao esquecimento. Assim, conviverão fontes de alimentação extirpadas, coolers exilados, carcaças de monitores, scanners tração a sangue e tecnologias DIY (Do It Yourself o Faça Você Mesmo) com telefonia celular avançada, processamento de áudio em tempo real (via PureData e/ou Max/MSP) e imagem digital. Serão fusionados sincreticamente a última geração e o obsoleto, o analógico e digital, o desenho de linhas sóbrias e elegantes e a evidente teia de cabos.

As atrizes com um"vestido/nu"(malhas cor pele que marcavam suas formas, as que além disso estavam detalhadamente desenhadas) não podiam escapar desse mundo que as invadia fisicamente, como invadia suas 
conversações (tal qual ocorre na vida diária). A ficção não podia estabelecer-se nesse universo mas, no entanto, a teatralidade se impunha, através dos corpos, os objetos, as imagens criadas, nesse teatro de pura apresentação.

Crave

Em Crave, uma encenação que Cristian Drut realizou em 2006 a partir do texto de Sarah Kane, os protagonistas do espetáculo eram o texto de Kane dito pelos atores que estavam sentados frente ao público e a iluminação produzida digitalmente.

A proposta era interessante porque se enfrentava com as formas estabelecidas. Podemos dizer que estamos em um teatro dramático pelo lugar preponderante que era dada ao texto? Já sabemos que a escritura de Kane é provocativa e, ainda que se possa fazer com ela uma montagem de forma tradicional, esta também permite experiências como a comentada aqui.

Aqui havia só ação verbal. Os atores, que não se moviam durante toda a peça, eram suportes do discurso. E isto tinha consonância com uma textualidade muito aberta, que só indicava as falas para as réplicas, sem determinar as personagens que falariam.

Mas a luz resultava outro ator da cena e, na realidade, era quem exercia todo o movimento cênico. No entanto não era somente luz o que se projetava. A cena se enchia de climas oníricos, de paisagens diversas, de ambientes abstratos. Ainda que os atores não os viam, pois estes ocorriam às suas costas, e apenas recebiam a iluminação, os atores (e também os espectadores, fascinados pelo que ocorria) de repente estavam em um não-lugar, no sentido de Marc Augé, e levavam o texto até ele.

Fabricio Costa Alisedo, o iluminador, explica assim seu trabalho:

A originalidade da encenação reside no uso de um software de concepção própria, Moldeo, que venho desenvolvendo desde 2002. Moldeo permite trabalhar com distintas camadas de imagens $e$ animações e modificar cada uma como se fossem telas independentes com graus de opacidade e cores ajustáveis no momento, que podem se mesclar e se esconder de forma dinâmica enquanto transcorre espetáculo. A luz sobre a cena se divide em formas recortadas sobre as personagens que são independentes entre si e ao mesmo tempo em relação com o fundo. Todos os fundos em si são independentes e isto permite infinitas combinações que estrutura a encenação. Apesar de existir um roteiro de luz, a obra com seu dinamismo impõe seus momentos e tem tons relacionados para criar e produzir alterações no estabelecido. $O$ efeito de iluminação se 


\section{Urdimento}

converte de alguma maneira em uma luz plástica graças à qual o artista visual se adapta sensivelmente ao contexto e o interpreta. ${ }^{11}$

Crudo

Aqui nos encontramos com um espetáculo claramente performático e fortemente tecnológico. A obra é uma realização de José María Muscari, um ator e diretor muito produtivo, que transita tanto no teatro independente como no comercial, que pode ser muito contestador ou mais tradicionalista. Trata-se de alguém difícil de rotular. A outra autora do espetáculo é Mariela Asensio, uma diretora muito original que também passou ao teatro comercial e que segue experimentando no teatro independente.

É interessante o que propuseram estes artistas nesta encenação: fazer uma obra absolutamente autobiográfica, na qual Muscari ator falasse dele, e na realidade fosse um performer que se expusesse ao público como tal, mostrando toda sua intimidade como fazia com seu corpo. Asensio foi a autora do roteiro e responsável da direção. Três atrizes acompanharam Muscari em números musicais nos quais este expunha suas habilidades para a dança.

Um teatro de apresentação no qual se trabalhou com o real: um fogão aceso que era utilizado (em cena se fazia básico e cheirava a fritura), um telefone com o qual Muscari se comunicava em tempo real com seus pais.

O espaço cênico se enchia de seus objetos de interesse, os aparelhos para a atividade física e o computador. Uma grande tela duplicava a tela do laptop no qual o ator lia seus e-mails, visitava seu blog ou seu Facebook. Os espectadores podiam escrutar o que fazia o ator/performer no seu computador, o que ele escrevia e o que recebia.

"Eu anuncio e exploro os limites da ficção e da realidade"disse Muscari em uma entrevista. Ele transpassava esses limites no espetáculo, mas a teatralidade que se criava no espetáculo e que Muscari e Asensio faziam crescer com música, canções, coreografias, com o histrionismo do ator, armava uma ficção cênica (um relato de ações e linguagens) atravessada pelo real (a voz dos pais, os vídeos da família, a tecnologia).

\section{Conclusões}

A cena conceitual é somente uma zona do teatro e nem ao menos é a mais importante. Nem ocupa todo o teatro performático. Está sim, dentro do leque das formas de experimentação. É raro que os teatristas façam somente este tipo de teatro. Estes vão e vem entre experiências diversas. Alguns, como Ana Alvarado e Emilio García Wehbi, tem mais tendência a recorrer este caminho. 
Certamente, o teatro canônico está longe de tudo o que vimos aqui, justamente porque o canônico necessita tempo de sedimentação, de processo e aqui estamos falando de buscas, de ações exploratórias.

Mas a arte é isso, buscas, trajetórias. As maiores dificuldades são encontradas no público, acostumado às formas consagradas e, ainda mais na crítica que tem dificuldade para absorver as buscas expressivas muito audazes.

No entanto, também nestes setores estão produzindo-se mudanças. Dolor exquisito permaneceu dois anos em cartaz com muito reconhecimento de crítica e público. Crave três anos. Body art dois anos. Um espetáculo tão arriscado como Visible de Ana Alvarado foi pensado para um ou dois meses e já está em cartaz há mais de três. Quase todos estes espetáculos tem estado muito tempo em cena.

Isso não representa todo o teatro de Buenos Aires, mas é um bom indício o fato de que se valorizem as renovações expressivas.

Richard Schechner diz em um artigo, se referindo às vanguardas dos anos 60 e 70, que tudo aquilo havia terminado, mas que suas marcas haviam ficado e haviam invadido outras formas de teatro. Podemos supor que algo assim ocorrerá com muitas destas buscas. Abrem um caminho que muitos seguirão de diferentes formas.

\section{Referências bibliográficas}

ALONSO, Rodrigo. Entre el documento y el espetáculo. El videoarte contemporáneo. Disponível em <www.territorioteatral.org.ar> n. 4, 2009.

ANTÚNEZ ROCA, Marcel-lí. Pro - Meta - Hiper - Membrana. Barcelona, Transversal / Centre d'Art Call Massó / Centre de Cultura Contemporània de Barcelona, 2009.

ARTAUD, Antonin. El teatro y su doble. Barcelona: Edhasa, 1978.

BADIOU, Alain and Elie During. s/d."A Theater of Operations. A Discussion" en AA.VV. A Theater without Theater, Barcelona, Museu d'Art Contemporani. BORJA-VILLEL, Manuel J. s/d."A Theater without Theater: The Place of the subjet"en AA.VV. A Theater without Theater, Barcelona, Museu d'Art Contemporani.

BOURRIAUD, Nicolás. El arte relacional. Buenos Aires: Adriana Hidalgo, 2008.

CALLE, Sophie. M’as-tu vue. Munich-Berlín-London-New York, 2008.

CORNAGO, Oscar. Resistir en la era de los medios. Estrategias performativas en literatura, teatro, cine y televisión, Madrid, Iberoamerican/Veruvert. Cap.:"“El espacio como cenario de resistencias: la escritura poética y el teatro pós-dramatico”, 2005. 
DAVIES, David. Art as performance. Oxford: Blackwell, 2004.

DIXON, Steve. Digital performance. A history of new media in theater, dance, performance art and installation. Cambridge (Massachusetts) - London: The MIT Press, 2007.

HOFFMANN, Jens and Joan Jonas. Perform. London: Thames and Hudson, 2005.

LEHMANN, Hans-Thies. Le thêatre posdramatique. Paris: L’Arche, 2002.

LONGONI, Ana. Conceitualismo. Disponível em: <www.territorioteatral. org.ar> n.1.

PAVIS, Patrice. La mise en scène contemporaine. Paris: Armand Colin, 2007.

SIBILIA, Paula. El hombre postorgánico. Buenos Aires: Fondo de Cultura Económica, 2009.

WEISS, Rachel."Rescribir el arte conceitual". In: Papers d'Art, n. 93, Girona, 2007. 